\title{
Moving Social Work Education Forward Through the Application of Neuroscientifically Informed Teaching Practice: A Case Study in Student Engagement Through Art and Multimodal Processing
}

\author{
David Axlyn McLeod
}

\begin{abstract}
Modern advances in neuroscience suggest learning occurs through three basic cognition patterns. Higher-level multimodal learning occurs when learning activities contain multiple cognition patterns. This case study details an application of these concepts where fine art, journaling, practicum experiences, and in-class processing were fused to create an active and participatory method of engaging social work students in critical thinking as related to differential impacts of clinical decision-making. The learning activities are described and multimodal learning is explained, along with the findings of a focus group used to assess student feedback. Student experiences and the potential adaptations of this approach are also addressed. The tentative findings of this case study indicate positive learning experiences and suggest a need for further research to explore the opportunities associated with the use of multimodal and art-infused learning techniques in social work courses.
\end{abstract}

Keywords: Social work education, neuroscience, art, multimodal learning, critical thinking, multimodal processing

Critiques of higher education have, for decades, suggested problems with apathetic students, ill-prepared graduates, incompetent teaching, and impersonal campuses (Chickering \& Gamson, 1987). In more recent history social work education has been likewise represented in this narrative as no different from the university at large when it comes to struggling to find ways to improve student engagement (Dooley, Sellers, \& Gordon-Hempe, 2009; Mendes, 2003). Further investigation is warranted to assess if apathy is truly to blame for these student engagement woes, or if new, creative approaches could be used to engage students not only in course content but also in relevant, connected, and meaningful learning experiences.

\section{Multimodal Learning}

Advances in cognitive neuroscience suggest learning to be a much more dynamic, visual, and spatial processing experience than traditionally thought (Blazhenkova \& Kozhevnikov, 2008). Through neuroimaging, Blazhenkova and Kozhevnikov (2010) found that the brain processes and stores information not only in verbal or text-based modes, but also through visual and interactive exchanges. This research builds on Gardner’s (1998) previous theory, which suggested humans have "multiple intelligences" including spatial, linguistic, kinesthetic, and others, from which the conceptualizations of "auditory" and "visual” learning styles were formed. Creating a practical application for this line of research, Groff (2013) proposed a theoretical framework for "wholemindedness" (p.16) which details the three primary cognitive pathways and speaks

David A. McLeod, PhD, MSW is an Assistant Professor at The University of Oklahoma Anne and Henry Zarrow School of Social Work.

Copyright @ 2015 Advances in Social Work Vol. 16 No. 2 (Fall 2015), 249-259, DOI: 10.18060/18590 
to the importance of engaging them holistically in learning activities. This framework suggests that multimodal learning environments, in which visualized, experiential, spatial, and verbal exchanges overlap, have the potential to produce more significant and widespread learning than traditional approaches since humans are not purely visual, spatial, or verbal learners. Instead, each individual learns through engagement in a unique combination of these cognitive pathways.

Multimodal approaches could be a key to opening up our capacity to engage social work students in more creative and meaningful ways. Previous research has suggested traditional teaching strategies, such as lectures, have less of an impact on student learning than active educational experiences where students are encouraged to think critically in order to solve complex problems (Lundahl, 2008). In this case study I introduce one example of the "wholeminded" learning approach and detail how it manifested in a semester-long educational activity.

\section{Methods of Interaction and Description of the Learning Experience}

The primary aim of the MSW course (Integrative Seminar) for which this activity was built was to teach critical thinking as it applied to clinical decision-making in social work practice settings. Clinical decision-making is an area of particular importance for new social workers in that it can be both a subjective and complex process to engage in, holding significant implications for the individuals, families, and communities that social workers aim to serve (Gambrill, 2005; Lacasse \& Gambrill, 2015). In order to help students better work toward this goal of proficiency in critical thought throughout the clinical decisionmaking process, a multimodal learning activity was created. This activity fused the explicit processing of clinical observations and activities from student practicum placements to reflective journaling, discussion, and the use of art for conceptual storytelling. This approach aimed to help students contemplate, process, and describe the differential impact of clinical decision-making on clients, their families and loved ones, communities, organizations, and themselves.

The incorporation and use of art-based learning experiences, while not widespread, is not new to social work education. Previous literature has suggested that arts-based materials can be highly successful at helping students explore personal schema, beliefs, worldviews, and systems with complexity while evoking deep emotional and cognitive connections (Keddell, 2011).

For this learning activity the choice was made to avoid the synthetic creation of reality. Rather than using role-plays or scenarios, students were tasked to recall and study real interactions from their practicum placement where they, or another social worker in their presence, had made a clinical decision. This approach was used to maintain an organic connection to the interactive observation. These recalled observations of clinical decisionmaking fulfilled the role of the spatial cognition for the activity. According to Groff (2013), these spatial interactions were neurobiologically processed through a distinct cognitive pathway that humans use to conceptualize and store information related to interactive exchanges. To document these experiences, students were asked to journal about at least 
one interactive observation each week and to process the differential implications of clinical decisions that were a part of those interactions.

In the learning activity students accessed their verbal/linguistic cognitive pathways in two primary ways. The first of these was through journaling about their clinical observations. In their journals students reflected about how clinical decisions they were involved in could impact the lives of others differentially. Students were asked to postulate how these decisions may have felt to the client, as well as others associated with that client (family, community, etc.) in the short and long term. Additionally, they were asked to write about possible implications of these decisions for their organizations and how these decisions affected them personally. Additional verbal/linguistic processing was incorporated into the learning activity by giving students in-class time weekly to recall and discuss these decisions as a group. Google Docs was used as a platform for the student journals, which allowed the instructor to assess, in real time, what students were journaling. This approach permitted the instructor to develop a plan for in-class discussions by synthesizing themes identified in student journals with pre-determined course content for that week. The instructor would begin class discussions by drawing parallels between the week's course content and themes from the journals. Students would be given the opportunity to engage with each other in relation to the experiences they had documented. The instructor did not identify individual students or what was written about in their journals. Instead, a collective learning environment that allowed students to openly share what they had been processing in their journals was created.

About three-quarters of the way through the semester, and after approximately eight entries, students conducted a content analysis of their journals to identify themes regarding the differential nature by which clinical decisions impacted stakeholders. Prior to this exercise, students were given a brief tutorial on the basic concepts of Grounded Theory, as defined by Strauss and Corbin (1998). The intent was not for students to engage in a full grounded theory exploration of their journals; however, several principles of the approach were used to help students organize the evaluation of their journals and to develop themes associated with the content. Students were taught how to open code the narrative data and how to organize and make meaning of these codes in order to develop personalized theories on the potentially differential impacts of clinical decision-making. Themes such as fear of engagement in treatment, frustration with mandated clinical intervention, relief after stabilization in care, pride from successful resolution in treatment, powerlessness in child welfare and other social protection systems, and many others were identified and related to the contexts of individuals, groups, families, and communities who are impacted by clinical decision-making. Then, through coordinating with the director of public engagement at a large university art museum, students were led by a museum docent on a tour through the museum and learned how artists use their artistic ability to visually communicate issues such as those found in the themes from their journals.

After the tour, students were asked to explore the museum on their own and find artwork that they believed could help them communicate the themes from their journals. Students were given a detailed handout to keep them on task and help them organize their thoughts on the themes they had developed from their journals and interpret the artwork they selected to communicate those themes (See Appendix 1 for an example of the 
handout). Students photographed (with permission) their selected artwork, and the following week used those photographs to present to the rest of the class. In these

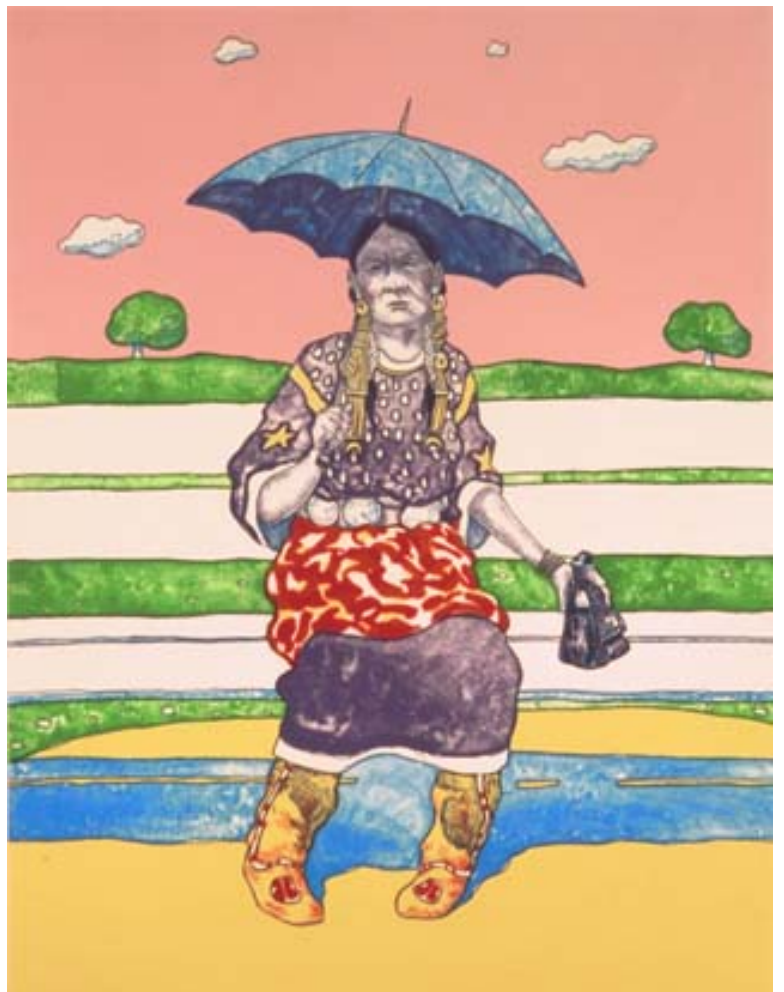

Figure 1. Waiting on a bus: Anadarko princess (Cannon, 1979) presentations students were expected to synthesize their interactions with clients and clinical decision-making with the themes they identified from their written journals and to use the art they identified to help tell the story of how they believed those themes were connected to the lives of their clients and the systems with which they intersect. This process was designed to intentionally use all three domains of cognitive processing (verbal, spatial, and visual) concurrently.

An example of these connections can be seen through a deconstruction of one of the student presentations. One student who had been journaling and verbally processing about their placement in a public mental health center which offered services centered on mental health, divorce, and family preservation selected the painting Waiting for a Bus: Anadarko Princess by T. C. Cannon (1979, see Figure 1). Through journaling, the student identified themes of powerlessness, endurance, and survival. In describing the painting, the student shared with the class how they saw a woman between two worlds, dressed traditionally but still holding an umbrella and waiting on public transit. The student spoke of trying to understand the look on the face of the Native women depicted in the painting, and noted how it came across as expressing displeasure or discomfort but also strength and pride. The student used the painting to help describe the powerlessness that clients may feel when they are told to make certain changes in their lives for which they may not be ready. The student also used the painting to talk about how clients often seem to endure situations when dealing with court-mandated treatment or intervention, and that success in the eyes of clients can often be closely related to survival and being able to finish treatment even when the choices being made about their lives do not align with what they may want for themselves at the time.

Through this multimodal learning project, students were given opportunities to gain awareness of the lived experiences of clients and process those experiences in their journals, giving them the opportunity to think more broadly about client perspectives. In the final presentations students demonstrated deeper learning as they incorporated the visual, spatial, and linguistic learning pathways they had been engaging in all semester into 
a singular experience. By using art to showcase the themes they had identified in their journals, students were able to connect, in meaningful ways both cognitively and emotionally, to the stories of the clients they served throughout the semester. Table 1 presents an organized description of the learning activity timeline with specific student and instructor tasks and product expectations, as well as their connection to cognitive processing domains during each part of the learning activity.

\begin{tabular}{|c|c|c|c|}
\hline \multicolumn{4}{|c|}{ Table 1. Multimodal Learning Activity Progression Throughout the Semester } \\
\hline & Cognition & & \\
\hline Timeframe & Type & Student Products & $\underline{\text { Instructor Tasks }}$ \\
\hline $\begin{array}{l}\text { Sessions } \\
2-9\end{array}$ & $\begin{array}{l}\text { Spatial and } \\
\text { Verbal } \\
\text { Cognition }\end{array}$ & $\begin{array}{l}\text { One journal entry each week } \\
\text { that details an observed or } \\
\text { enacted clinical decision } \\
\text { from practicum and that } \\
\text { postulates how that decision } \\
\text { could impact clients, their } \\
\text { families, the organization, } \\
\text { and the social worker } \\
\text { differentially }\end{array}$ & $\begin{array}{l}\text { - Monitor journal entries and } \\
\text { provide individual feedback } \\
\text { - Assess journal entries for } \\
\text { themes across students } \\
\text { - Use those themes to } \\
\text { facilitate in-class group } \\
\text { discussions and decision- } \\
\text { making processing with } \\
\text { students }\end{array}$ \\
\hline $\begin{array}{l}\text { Sessions } \\
10-13\end{array}$ & $\begin{array}{l}\text { Verbal } \\
\text { Cognition }\end{array}$ & $\begin{array}{l}\text { - Students use content analysis } \\
\text { to code their journals and } \\
\text { identify themes of } \\
\text { differential experience and } \\
\text { perspective and add notes on } \\
\text { the process and key themes }\end{array}$ & $\begin{array}{l}\text { - In week } 10 \text { provide an } \\
\text { overview of qualitative } \\
\text { coding } \\
\text { - } \text { Provide examples of } \\
\text { expected themes from earlier } \\
\text { interactions with journals }\end{array}$ \\
\hline $\begin{array}{l}\text { Session } \\
14\end{array}$ & $\begin{array}{l}\text { Visual } \\
\text { Cognition }\end{array}$ & $\begin{array}{l}\text { - Students will engage in } \\
\text { discussion on perspective } \\
\text { during a guided tour at the } \\
\text { art museum (taking notes). } \\
\text { - (Directly following the tour) } \\
\text { Students go out on their own } \\
\text { to identify and document } \\
\text { works of art that can help } \\
\text { them communicate themes } \\
\text { from their journals }\end{array}$ & $\begin{array}{l}\text { - Plan well ahead of time with } \\
\text { the museum staff to } \\
\text { coordinate the tour and } \\
\text { communicate the } \\
\text { fundamentals of the } \\
\text { assignment } \\
\text { - Create a worksheet to guide } \\
\text { students through the } \\
\text { museum experience } \\
\text { - Monitor to ensure student } \\
\text { engagement at the museum }\end{array}$ \\
\hline $\begin{array}{l}\text { Session } \\
15\end{array}$ & $\begin{array}{l}\text { Spatial, } \\
\text { Verbal, \& } \\
\text { Visual } \\
\text { Cognition }\end{array}$ & $\begin{array}{l}\text { - Students will show a picture } \\
\text { of the art they chose and } \\
\text { present to the class how it } \\
\text { connects to their themes } \\
\text { from their journals and how } \\
\text { those themes were coded } \\
\text { and developed }\end{array}$ & $\begin{array}{l}\text { - Make sure the class is } \\
\text { engaged in reflective } \\
\text { questioning during student } \\
\text { presentations }\end{array}$ \\
\hline
\end{tabular}




\section{Student Feedback and Lessons Learned}

At the conclusion of the semester, a focus group was conducted to explore student perceptions of their multimodal learning experience. Students were advised that data collected from the focus group, in addition to being used for learning activity refinement, would be used for dissemination. All fifteen students consented to participate and were given the option to withdraw at any time and for any reason, as well as the opportunity to come forward and choose how their comments would be used. At the end of the focus group, students worked together to member check major themes that had been identified and helped to refine the interpretation of their experiences as associated with the multimodal learning activity. Students were eager to offer suggestions and worked collaboratively in this process. Through an examination and analysis of their feedback, and in partnership with the students as they participated in the focus group, three primary themes were identified.

\section{Alternative Educational Activities Can be Intimidating}

The first of these themes suggested that alternative learning activities, such as this one, were not the norm for the students. Students suggested they were initially confused, scared, and worried about if they would be able to competently fulfill the requirements of the activity. However, throughout the semester and likely due to thorough descriptions of activity expectations along the way, the instructor observed that student self-efficacy rose. In fact, it appeared that at the later stages of the activity students more comprehensively recognized their ability to participate successfully. One student stated, "All the way up until we got to the museum I was going, 'I'm not creative, I can't do this.' But then once the tour started I got into it. It just kind of clicked.” This feedback suggests that it is important to be as detailed and transparent about the expectations of this type of exercise as possible. These students were interested but initially hesitant to participate; however, descriptive instructions and consistent feedback were found helpful in relieving their anxiety about how their performance would be assessed and ultimately helped students feel comfortable fully engaging in the learning activity.

\section{The Benefits Started Far Before Arrival at the Museum}

One of the more unexpected themes centered on how earlier stages of the activity were far more beneficial to students than had been originally anticipated. Students found the journaling and in-class discussions about their journals to be remarkably helpful to their learning. One student observed, "the journal was actually really therapeutic for me." Students also found positive learning opportunities in processing the narrative data from their journals. When talking about that experience, one student said, "it was actually the end of the semester when we were doing the analysis of our entries that I started to see some of the same themes, like frustration, in both what I was describing about the client experience and that of the social worker." These higher level processing activities demonstrated the nuances of critical thought used in this activity by facilitating opportunities for students to reflectively assess their own experiences, as well as the experiences of their clients, and were excellent teaching and learning resources that aligned with course goals. 


\section{It is the Final Reflective Experience That "Brings it All Together"}

While there were specific benefits throughout the semester's activities, students expressed how the final processing experience at the art museum was pivotal to their learning. One student said, “you know it's one thing when you're journaling, talking, or processing about this stuff (in class), but when you are really having to think about it and then you stand there in front of that piece of art and the whole thing just slaps you in your face and it's like, duh, now I really get it.” Interpretation of student feedback suggested that this learning experience was complex and, though each of the individual parts was important, the combination of them was greater than the sum of its parts. From journaling, to analysis, to introspection and processing, through finding art to communicate themes and presenting their findings to classmates, each stage of the learning activity built on the stage(s) that came before it and made the overall learning experience more meaningful.

Student feedback suggested the experience as a whole to be transformative. One student said, "this assignment really challenged me and forced me to think abstractly" while another shared, "using the qualitative analysis with our journaling and pulling in artwork to think about alternative client perspectives was by far the best experience I have had in college."

\section{Discussion}

Multimodal learning experiences present promising opportunities for social work educators to engage students in activities that complement a variety of learning styles. However, several potential limitations exist to this approach as well as the assessment of its impact on student learning. The first of these is that the activity has not been empirically tested. Feedback, as described above, is from a single case study of 15 students in one semester. Additional student evaluation is needed to further assess the impact of the activity on student learning. Additionally, the assessment and evaluation techniques to quantify learning need to be further refined. Supportive institutional resources will also vary. In this case, the learning activity took place at a large research university with substantial resources, such as an on-campus museum of fine art and staff at that museum who could assist in helping students learn how to process and interpret the art during the learning experience.

However, while these resources certainly influence the experience, the learning activity could undoubtedly be adapted. Students could easily identify art found through online resources to connect to the themes developed in their processing of a variety of topics. Coordination with off-campus, local, regional, or other resources could also be used to give students the opportunities to experience their cognitive processing in formal museums or spaces that curate artistic works. Considering that one of the major tenets of the activity is to teach students how to think creatively to process the nuances of social work interactions, instructors would be well-served to model for students the identification of creative methods to help them access and process art for the activity.

In contrast to previous finidings, social work students do not appear to be apathetic recipients of knowledge. They are eager to learn, keen to move past PowerPoint, and hungry for experiential learning opportunities. This case study details an attempt to fuse 
the concepts of evidence-based neuroscience on learning with a creative and engaging approach to social work education. While this learning activity is based on evidence from the neuroscience literature, it should not be considered an evidence-based teaching practice at this time. Further assessment is needed to empirically validate the approach used in this study. Preliminary student feedback suggests the learning activity is highly successful and engaging. This is, however, an activity where the core concepts could easily be adapted and incorporated into courses on diversity and oppression, children and families, or a variety of other complex topics to encourage multi-layered conceptualization. Interweaving verbal, spatial, and visual processing activities to create multimodal learning environments holds great promise for social work education as a whole and needs to be further explored.

If social work educators are teaching students to work on the cutting edge of social work with evidence-based practices, then we should be working to bring ideas from outside of the profession to advance our teaching practices, continually evaluating the efficacy of these approaches, and assessing their impact on student learning. Surely if it is our goal to help students learn how to fully engage with the clients we seek to serve, then enhancing the ways by which we engage in their learning could be a pivotal first step in that process.

\section{References}

Blazhenkova, O., \& Kozhevnikov, M. (2008). The new object-spatial-verbal cognitive style model: Theory and measurement. Applied Cognitive Psychology, 23(5), 638663. doi: htt://dx.doi.org/10.1002/acp.1473

Blazhenkova, O., \& Kozhevnikov, M. (2010). Visual-object ability: A new dimension of nonverbal intelligence. Cognition, 117(3), 276-301. doi: htt://dx.doi.org/10.1016/j.cognition.2010.08.021

Cannon, T. C. (1979). Waiting on a bus: Anadarko princess [painting].

Chickering, A., \& Gamson, Z. (1987). Seven principles for good practice in undergraduate education. American Association for Higher Education Bulletin, 40(7), 3-7.

Dooley, J., Sellers, S., \& Gordon-Hempe, C. (2009). Lemons to lemonade: How five challenges in teaching macro practice helped to strengthen our course. Journal of Teaching in Social Work, 29(4), 431448. doi: $\underline{\text { htt://dx.doi.org/10.1080/08841230903249760 }}$

Gambrill, E. (2005). Critical thinking in clinical practice. Hoboken, NJ: John Wiley.

Gardner, H. (1998). Are there additional intelligences? The case for naturalist, spiritual, and existential intelligences. In J. Kane (Ed.), Education, information, and transformation (pp. 111-131). Upper Saddle River, NJ: Merrill-Prentice Hall.

Groff, J. S. (2013). Expanding our "frames" of mind for education and the arts. Harvard Educational Review, 83(1), 15-39. doi: htt://dx.doi.org/10.17763/haer.83.1.kk34802147665819 
Keddell, E. (2011). A constructionist approach to the use of arts-based materials in social work education: Making connections between art and life. Journal of Teaching in Social Work, 31(4), 400-414. doi: htt://dx.doi.org/10.1080/08841233.2011.597678

Lacasse, J. R., \& Gambrill, E. (2015). Making assessment decisions: Macro, mezzo, and micro perspectives. In B. Probst (Ed.), Critical thinking in clinical diagnosis and assessment (pp. 69-84). New York: Springer.

Lundahl, B. W. (2008). Teaching research methodology through active learning. Journal of Teaching in Social Work, 28(1-2), 273-288. doi: htt://dx.doi.org/10.1080/08841230802179373

Mendes, P. (2003). Teaching social policy to social work students: A critical reflection. Australian Social Work, 56(3), 220233. doi: htt://dx.doi.org/10.1046/j.0312-407x.2003.00079.x

Strauss, A. L., \& Corbin, J. M. (1998). Basics of qualitative research: Techniques and procedures for developing grounded theory. Thousand Oaks: Sage.

\section{Acknowledgements}

I would like to offer a sincere thanks to the students who engaged with me in this process. I have learned a great deal from you all and hope that in sharing our experience with others we can broaden the conversation around unique experiences of class interaction in social work education. I would also like to thank Ms. Sue Schofield, Museum Docent, whose collaborative effort allowed us to construct a meaningful and engaging experience that has forever changed the way I see art.

\section{Author note}

Address correspondence to: David A. McLeod, PhD, MSW, The University of Oklahoma Anne and Henry Zarrow School of Social Work, 700 Elm Ave, Norman, Oklahoma, 73019. Email: damcleod@ou.edu 
Appendix A

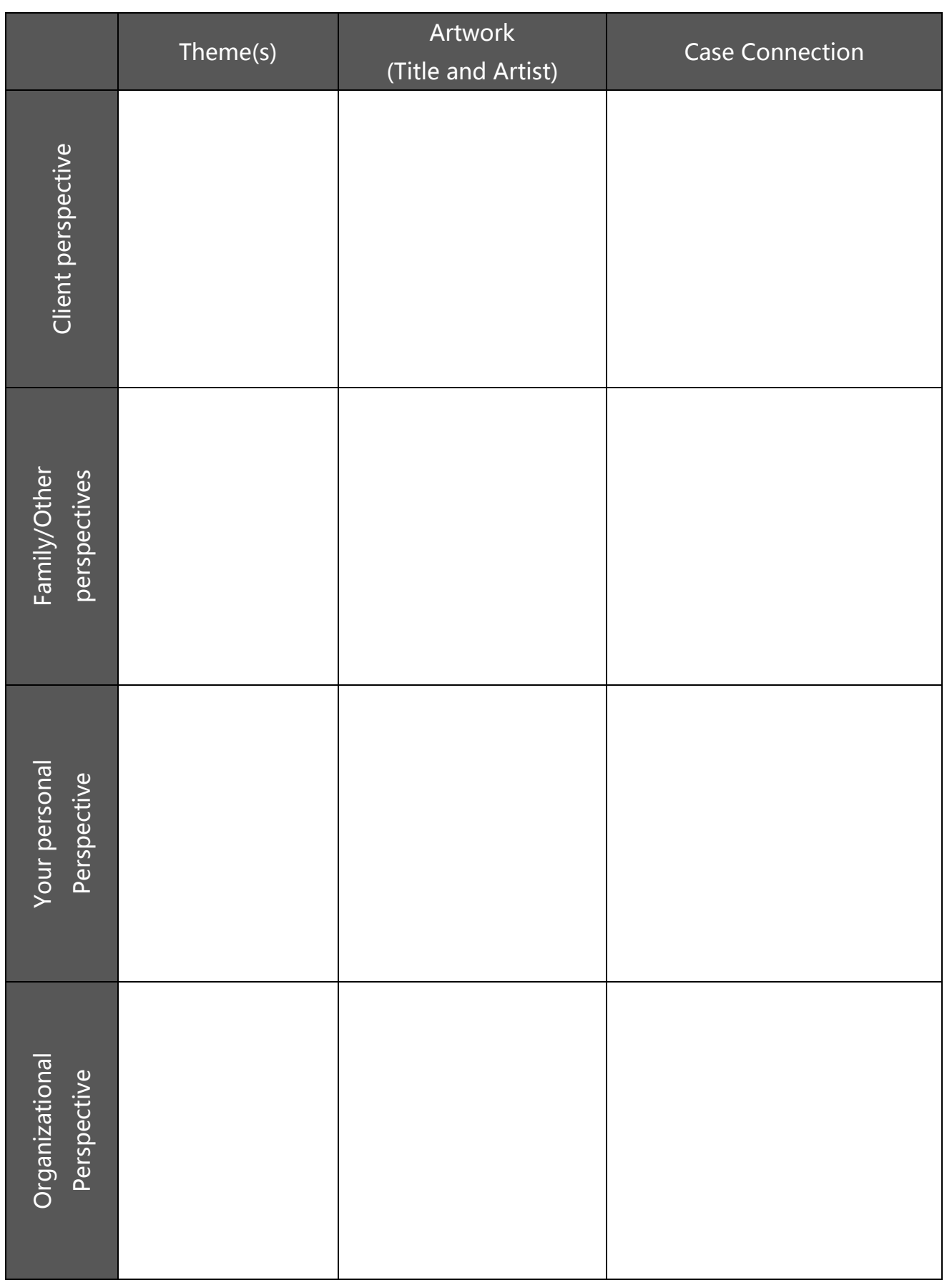


Purpose:

- $\quad$ Students are to take this opportunity to process seeing the world from the perspectives of others.

o Specifically, students will think through how they have observed the differential impact of clinical decision-making in professional social work practice, and will identify works of art that can help the share the stories of those differential experiences.

o Prior to this process students will engage in a tour and discussion centered on artist and subject perspective and how the use of light, color, staging, and other artistic mechanisms help artists communicate themes and situations and tell stories of human experience and interaction with the world.

Directions:

- Use this sheet to help organize your process through the museum

o Take notes!

- $\quad$ Find artwork to help tell the story

o You are looking for pieces that connect to the themes you found in your journal

o BE CREATIVE

O Use your imagination

- This is a skill that will perhaps help you more than any other in social work practice. Remember that.

o There are no right or wrong answers

- $\quad$ Activity

o Take advantage of this time to connect as many pieces of art to your themes as possible

0 It is mandatory that you make at a connection to at least two themes

o Use this form for notes

- YOU WILL BE TURNING IT IN NEXT WEEK.

- Write down your themes before you get started

- Remember to list the artist and title of the artwork

- Take notes on how it connects

- Don't plan on doing this later. You will forget.

- REMEMBER to take a picture of the artwork with your phone (or whatever else)

- I have a camera if you need it, let me know

- Email the picture of the artwork you have chosen to present on, to me at professor@university.edu

- Next week

- I will make a photo album in our Facebook group

o What to turn in

- This paper with your notes on it

- A one page bulleted write-up outlining the connection between your chosen artwork and the case(s) its themes came from

o Presentations are 5 minutes or less 